Sir,

\section{Re: Winter pressures. What are they? What can be done to prevent them?}

Flemming's editorial on winter pressures ${ }^{1}$ presents interesting epidemiological data on winter peaks in respiratory infections, and is important reading for clinicians and administrators concerned with the impact and outcomes of these illnesses. These data and the recent King's Fund report on NHS winter pressures ${ }^{2}$ reveal that respiratory infections are the main cause of the recurrent workload and logistic crises that face us each winter. Acute bronchitis is identified by Flemming as the main cause of pressure on primary and secondary care services and as a major factor in the peaks in mortality rate that occur shortly afterwards.

As he points out, surprisingly little is known about the epidemiology and the pathogenesis of acute lower respiratory tract infections (LRTI). Although he states that the epidemiology is more consistent with a viral than a bacterial cause, a prospective study of LRTI in the community found bacteria to be isolated more commonly than viruses when a pathogen could be identified. ${ }^{3}$ Due to the concerns about increasing antimicrobial resistance in bacteria, GPs and the general public have been under pressure to limit antibiotic usage in the community, ${ }^{4}$ and there has indeed been a marked reduction in antibiotic usage in the UK over recent years. Of some concern however are reports of increasing winter excess mortality rates for community acquired pneumonia. ${ }^{5}$ While it is almost certainly true that for the majority of patients acute LRTI is a relatively minor and a self-limiting condition, for some patients it can result in a severe and life-threatening illness, and one in which prompt use of antibiotics can improve outcomes.

There is a pressing need for research to tell us which patients have a minor illness and which patients have a more serious illness and require antibiotics. Until we have this information, we need to do everything we can to improve outcomes for our patients and to reduce winter pressure on the NHS.

Maximising vaccination uptake is clearly one way to achieve this, but it seems to me prudent to consider antibiotic treatment in at-risk groups, such as the elderly and those with COPD or other significant co-morbidity, and to encourage all patients to report a worsening illness.

\section{Dr Mike Thomas}

Prim Care Resp J 2002; 11(4):133

GPIAG Research Fellow, Department of General Practice, University of Aberdeen

GP Minchinhampton, Gloucestershire

Hospital Practitioner Respiratory Medicine, Stroud

\section{References}

1. Flemming D. Winter pressures. What are they? What can be done to prevent them? Prim Care Resp J 2002;11(3):86-87.

2.Damiani M and DIxon J. Managing the Pressure. 2002. London. London The Kings Fund.

3. Macfarlane J, Holmes W, Gard P, et al. Prospective study of the incidence, aetiology and outcome of adult lower respiratory tract illness in the community. Thorax 2001;56:109-114.

4. Standing Medical Advisory Committee, Sub-group on

Antimicrobial Resistance. The path of least resistance. 1998.

London, Stationary Office.

5. Price D, Honeybourne D, Little P, Mayon-White R, Read RC, Whale M, Fitzgerald P, and Weston AR. Recent trends in GP antibiotic prescribing practice: a potential link to increased community-acquired pneumonia mortality. Thorax 2001:56(Suppl 3); S79.

\section{Sir,}

The study reported by Macfarlane et al reported on 316 adult patients selected out of 638 consulting with lower respiratory tract infection during one year in a large suburban practice. Pathogens (often multiple) were found in $173(55 \%)$ of cases. Cases were recruited up to 21 days following onset of illness. Whilst data were not presented on the interval between symptom onset and consultation, we need to be aware of the limitation on virological investigation arising from delay. Nevertheless viral culture was complemented by serological investigation.

During influenza epidemics commonly seen at the height of the winter pressure period, swabs from patients with influenza like illness submitted as part of routine surveillance from the RCGP sentinel network have disclosed influenza positivity as high as $50 \%$. This rate averages about $30 \%$ in the winter season: additionally approximately $20 \%$ positivity for Respiratory Syncytial virus has been observed (Zambon MC, Stockton JD, Clewley JP, Fleming DM. Contribution of influenza and respiratory syncytial virus to community cases of influenza-like illness: an observational study. (Lancet 2001;358: 1410-16)

We have a chicken and egg situation; which comes first? I suspect viral epidemic illnesses damage the lining of the respiratory tract and baceria which may even be commensals, invade the damaged tissue.

Certainly both Thomas and I are agreed that the aetiology of respiratory infection is inadequately researched and poorly understood.

\section{Dr. Douglas Fleming}

Prim Care Resp J 2002; 11(4):133

Director Birmingham Research Unit, 54 Lordswood Road, Harborne

Birmingham, B17 9DB

Tel: +44 (0)121 4261125

Sir,

\section{Winter pressures - more than simply infection?}

Fleming's editorial highlights the impact of respiratory disease, especially acute bronchitis, on death rates and use of NHS services in winter. However, recent analysis of London's hospital episode statistics suggest that acute infection is only part of the story.

In London, the most common cause of emergency medical admissions over the Christmas/ New Year period is chronic lower respiratory disease, especially chronic obstructive pulmonary disease (COPD) in those aged over 65 years. Numbers of these admissions, and bed days used for patients with respiratory disease, consistently peak in the first few weeks of January each year. The overall volume of these admissions is closely related to the prevalence of influenza, but since the timing of the peak in admissions is always at almost exactly the same time each year (both in London and across England) other potential causes for these peaks must be considered.

Respiratory syncitial virus incidence is highest each mid-winter, but 